\title{
Development Time Variability: Adaptation of Régnière's Method to the Intrinsic Variability of Belgian Lucilia Sericata (Diptera, Calliphoridae) Population
}

\author{
M. Gosselin ${ }^{1,2 *}$, D. Charabidze ${ }^{3,4}$, C. Frippiat ${ }^{5}$, B. Bourel ${ }^{3,4}$, D. Gosset $^{3}$ and P. Rasmont ${ }^{1}$ \\ ${ }^{1}$ Université de Mons, Laboratoire de Zoologie, B-7000, Mons, Belgium \\ ${ }^{2}$ Institut National de Criminologie et de Criminalistique, laboratoire de toxicologie, B-1120, Bruxelles, Belgium \\ ${ }^{3}$ Univ Lille Nord de France, Institut Médico-légal, F-59000 Lille, France \\ ${ }^{4}$ UCLille, labo EandS, F-59000 Lille, France \\ ${ }^{5}$ Institut National de Criminologie et de Criminalistique, laboratoire d'analyse génétique, B-1120, Bruxelles, Belgium
}

\begin{abstract}
Development times and survivorship of Lucilia sericata (Meigen, 1826) were measured for different constant temperatures. In addition, lower threshold ( $\mathrm{tL}$ ) and thermal constant $(\mathrm{Kt})$ were estimated for a local population. The estimated development time calculated from mean or minimum development time induces a bias that may be reduced using a model of intrinsic variability. In order to quantify variation in emergence rate during the development time, a simulation method was developed by adapting the Régnière's method. The adapted model allowed accurate prediction of the emergence profile of $L$. sericata at constant temperature in the linear portion of the development curve. We believe that the application of this method in forensic entomology cases could increase the reliability of the conclusions of an entomological Post Mortem Interval (PMI) estimation.
\end{abstract}

Keywords: Blowflies; Forensic science; Development speed; Mortality

\section{Introduction}

Development duration of Lucilia sericata (Meigen, 1826) (Diptera: Calliphoridae), as for many other insects, depends on temperature. This relationship is curvilinear at low and high temperatures and linear in-between [1]. However, even at a chosen temperature, a large variability in development times is observed within published data [2-6].

This variability is largely due to inter-individual competition $[7,8]$, food type $[9,10]$ or nyctemeral rhythm $[6,11]$. Such variability could also result from different experimental designs $[6,11]$. Furthermore, the given development time are mainly based on summary statistics such as minimum $[3,12]$, median $[5,13,14]$, mean $[2,15]$, maximum [3] or percentage $[1,4,16]$. The use of these different sampling methods and types of synthetic parameters could bias the accuracy of the final published development data [14]. Therefore, Wells and Lamotte [17] promote the use of full distributions instead of summary values.

To include this intrinsic variability in development-time duration estimation, Régnière [18] describes a method based on a correction factor handset to median developmental value. Interestingly, median is an often used synthetic value and is recommended by Richards and Villet [14] in the context of forensic entomology. A more recent publication suggests a parameter estimation procedure for time distributed delay (TDD) models [19]. But this process is, however, limited to symmetric development distributions [19].

The present study estimates the survivorship and summary values of development for a Belgian Lucilia sericata population at different constant temperatures. Using this dataset, we described an adaptation of Régnière's method to simulate intrinsic variability on $L$. sericata development speed. The adapted method has also been used to simulate emergence curves from experimental data.

\section{Material and Methods}

\section{Experimental data}

Larvae of the blowfly Lucilia sericata were collected from a field in Brussels (National Institute of Criminology and Criminalistics, Brussels, Belgium). The flies were held in an insectarium at $24 \pm 2^{\circ} \mathrm{C}$ with $70 \pm 5 \%$ relative humidity $(\mathrm{RH})$ and a photoperiod of L16:D8 and fed ad libidum with water, sugar, powdered milk and brewer's yeast.

For oviposition, a piece of beef heart was provided within 4 hours. The time when the beef heart was removed from the cage was recorded as the beginning of development [16]. Eggs batches were collected from this piece and about 200 eggs were deposited on $250 \mathrm{~g}$ of beef heart in a plastic box [16]. Experiments were conducted in incubators (Sanyo, Incubator MIR 553) set at constant temperatures of $12.5,15,20,25,30,35$ or $37.5 \pm 1{ }^{\circ} \mathrm{C}$ with a photoperiod of L12:D12. A data logger (Testo, 174) was inserted into the incubators to monitor the temperatures each hour. This procedure was repeated at minimum 8 times for each temperature regime except for mortality at $20^{\circ} \mathrm{C}$. Successfully emerging adults were recorded daily and removed from the box [14].

\section{Description of the analytical method}

Reduced major axis regression [20] was used to calculate lower

*Corresponding author: Matthias Gosselin, National Institute for Criminalistics and Criminology, laboratorium of toxicology, Brussels, Belgium, E-mail: matthias. gosselin@just.fgov.be

Received December 09, 2010; Accepted December 28, 2010; Published December 30, 2010

Citation: Gosselin M, Charabidze D, Frippiat C, Bourel B, Gosset D, et al. (2010) Development Time Variability: Adaptation of Régnière's Method to the Intrinsic Variability of Belgian Lucilia Sericata (Diptera, Calliphoridae) Population. J Forensic Res 1:109. doi:10.4172/2157-7145.1000109

Copyright: (c) 2010 Gosselin M, et al. This is an open-access article distributed under the terms of the Creative Commons Attribution License, which permits unrestricted use, distribution, and reproduction in any medium, provided the original author and source are credited. 


\begin{tabular}{|l|l|l|l|}
\hline Temperature $\left({ }^{\circ} \mathbf{C}\right)$ & $\begin{array}{l}\text { No of repetitions } \\
\text { (and pupae) }\end{array}$ & Emergence (\%) & Standard Error (\%) \\
\hline 12.5 & $12(1366)$ & 22.8 & 12.7 \\
\hline 15 & $18(1171)$ & 44.3 & 12.1 \\
\hline 20 & $4^{\mathrm{a}}(583)$ & 65.9 & 27.4 \\
\hline 25 & $12(2389)$ & 85.7 & 10.7 \\
\hline 30 & $10(2061)$ & 95.4 & 6.6 \\
\hline 35 & $12(2754)$ & 40.7 & 14.8 \\
\hline 37.5 & $8(579)$ & no emergence & \\
\hline
\end{tabular}

aPercentage of emergence was counted only on 4 treatments and not for the totality of treatments at $20^{\circ} \mathrm{C}$

Table 1: Percentage of pupae to successfully emerge as adults of Lucilia sericata reared under constant temperatures and photoperiod of L: D 12: $12 \mathrm{~h}$

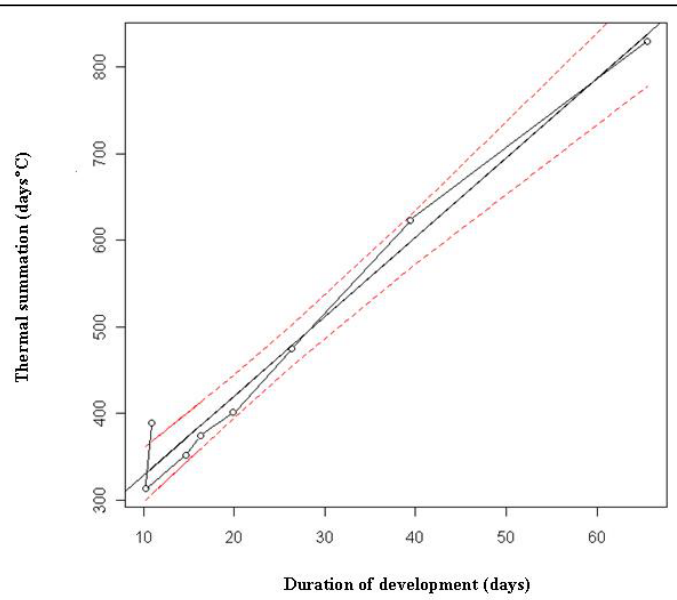

Figure 1: S-shaped curves and reduced major axis regression lines used to determine $\mathrm{Kt}$ and $\mathrm{t}$ values of Lucilia sericata at 6 constant temperatures for emergence. White and black circles indicate respectively median development time used and not used in the regression calculations and dotted lines represent $95 \%$ confidence intervals.

threshold $\left(\mathrm{t}_{\mathrm{L}}\right)$ and thermal constant $(\mathrm{Kt})$ from the median development time at each temperature $[13,14]$.

In Régnière's method, the proposed distribution function is polynomial. However, in this study, we have used Weibull distribution function [21], which allows equivalence between the mean and the median. Thus, most of published data from previous forensic entomology studies could be used. Two-sample Kolmogorov-Smirnov tests were applied to test the reliability between emergence profiles of $L$. sericata observed experimentally and based on Régnière's simulations. All analyses were conducted using open source software R-2.8.1.

\section{Results}

\section{Standard development of population}

Between 12.5 and $30^{\circ} \mathrm{C}$, the percentage of emergence increased with increasing temperature. At $35^{\circ} \mathrm{C}$, the percentage of emergence starts to decrease, and finally at $37.5^{\circ} \mathrm{C}$ no pupae eclosed (Table 1). In this temperature range $\left(12.5-30^{\circ} \mathrm{C}\right)$, the median development times of Lucilia sericata have a linear relationship with temperature $\left(\mathrm{R}^{2}=0.99\right)$ (Figure 1). Development times (days) of Lucilia sericata decreased with higher temperatures. The lower threshold $\left(t_{L}\right)$ for total development is $9.55 \pm 0.41(\mathrm{SD})^{\circ} \mathrm{C}$ and the thermal constant (Kt) for Lucilia sericata was $217.97 \pm 15.01(\mathrm{SD})$ Degree Days above the threshold.

\section{Intraspecific variability modelisation by adapted Régnière's method}

According to Régnière's recommendations, population was divided for each temperature into sub-populations, each corresponding to an
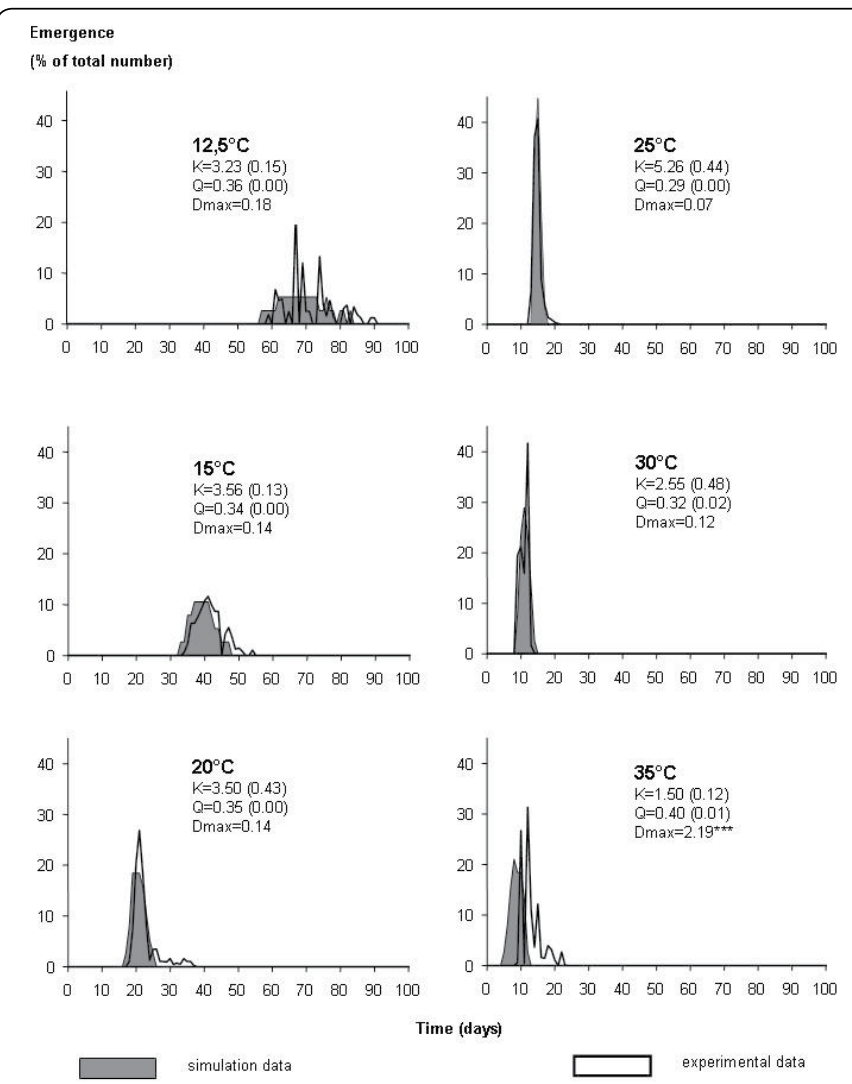

Figure 2: Comparison at different constant temperatures between profiles emergence of $L$. sericata observed experimentally and in simulation. Asterisks (Kolmogorov-Smirnov ${ }^{* * *} p<0.001$ ) indicate profiles emergence that differ statically between observed and simulated data. Parameters $K$ and $Q$ are indicated in each figure with standard error and statistics. W is indeed constant and thus independent of temperature.

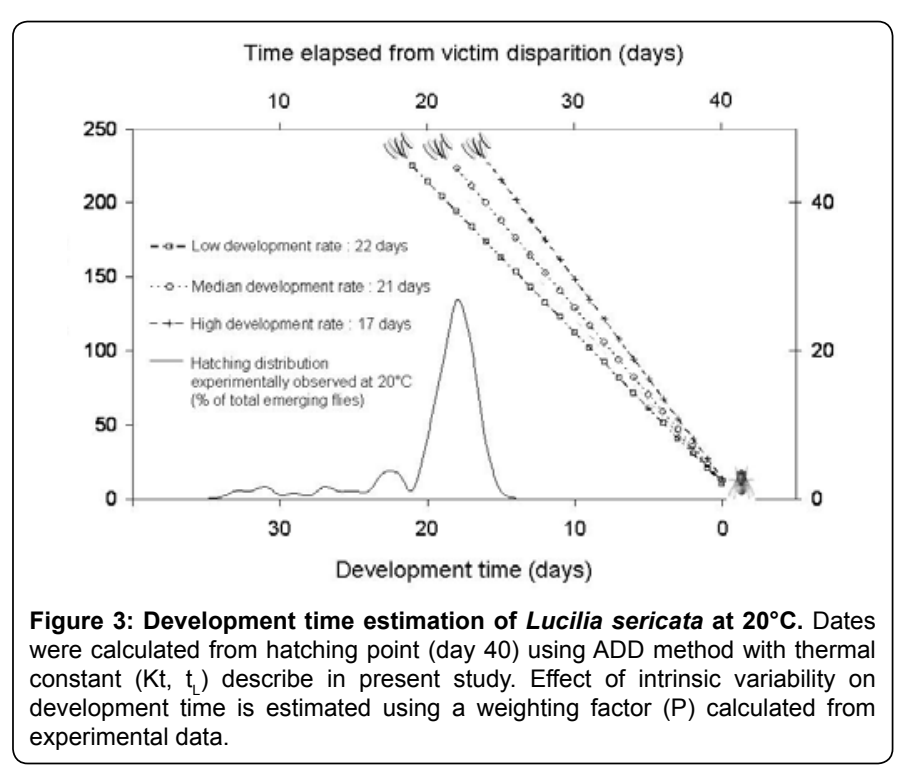

equal part of the whole population. Thus, the Weibull distribution law's fitting parameters $(\mathrm{W}, \mathrm{K}$ and $\mathrm{Q})$ and statistics were determined and are summarized in Figure 2. Finally, replacing $W, K$ and $Q$ in Régnière's equation gives the correction factor $\mathrm{P}$ to apply for each percentile of population. 
Then, we multiply the median accumulated degree-days (ADD) by weighting factor $(\mathrm{P})$ relative to each sub-population and temperature to obtain weighted value $(\mathrm{ADDw}=\mathrm{ADD} \times \mathrm{P})$. As a result, the curve of emergence could be rebuilt by addition of these values until $\Sigma$ $\mathrm{ADDw}=\mathrm{Kt}$. Only at $35^{\circ} \mathrm{C}$, the emergence profiles differ statistically between observed and simulated data.

The usefulness of this adapted method is demonstrated by forensic entomological example. We considered the case of an adult L. sericata emerging on day 40 at ambient temperature (Figure 3). Using minimum development times, oviposition will be placed on day 20. However, this emergence can also result from oviposition at day 19 until day 12 if respectively the median or the maximum development times are used. The probability of each one of these hypothesis can then be determined from the sampling rate.

\section{Discussion}

According to Wall et al. [7], the percentage of emergence is temperature dependant and extremely variable, ranging from 0 to $96 \%$. By contrast of the present study, emergences of adults were observed at $15^{\circ} \mathrm{C}$ by Grassberger and Reiter [4].

Analysis of these developmental data revealed that emergence profiles of single population at different constant temperatures demonstrate a large variability, due to a different individual development rate. Unfortunately, this intrinsic variability is not-well mentioned and studied in forensic studies. The proposed model describes the intrinsic variability of a local population and can accurately predict the emergence profile of $L$. sericata at constant temperatures.

In addition, this method could be applied for forensic PMI estimations. Thus, a complete interval for the PMI estimation can be obtained, which is of interest in forensic cases with multiple ovipositions occurring all over the time of decomposition [22]. Indeed, the best way to obtain oldest larvae (which are considered to be the most representative indicator of the first oviposition event), is gathering a large sample (i.e. at least 30 individuals) [23]. But in many cases, the sample is insufficient. Thus, using minimum, mean, median or maximum development time from first emergence could become tricky [22]. As an example of application, the adapted Régnière's model allows estimating the whole oviposition window susceptible to lead to an emergence point. Thus, intrinsic variability can be integrated by using this method, and so reliability of entomological expertise could be increased. However, this method must be applied in a long-term study including different experimental and human cases to confirm increase of reliability.

\section{Acknowledgements}

The authors wish to thank, D. Michez and G. Morvan for scientific support, $\mathrm{T}$. Boonen, J. Karapetian and K. Vits for their technical help in sampling, J.-F. Godeau, P. Grosjean and X. Simon for their statistical help and R. Shelby, K. de Wael and S. Wille for their useful comments.

\section{References}

1. Grassberger MD, Reiter MD (2002) Effect of temperature on development of Liopygia (=Sarcophaga) argyrostoma (Robineau-Desvoidy) (Diptera: Sarcophagidae) and its forensic implications. J Forensic Sci 47: 1-5.

2. Ash N, Greenberg B (1975) Developmental temperature response of the sibling species Phaenicia sericata and Phaenicia pallescens. Ann Entomol Soc Am 68: $197-200$

3. Anderson GS (2000) Minimum and maximum development rates of some forensically important Calliphoridae (Diptera). J Forensic Sci 45: 824-832.

4. Grassberger M, Reiter C (2001) Effect of temperature on Lucilia sericata (Diptera: Calliphoridae) development with special reference to the isomegalen and isomorphen diagram. Forensic Sci Int 120: 32-36.

5. Bourel B, Callet B, Hédouin V, Gosset D (2003) Flies eggs: a new method for the estimation of short-term post-mortem interval? Forensic Sci Int 135: 27-34.

6. Tarone AM, Foran DR (2006) Components of developmental plasticity in a Michigan population of Lucilia sericata (Diptera: Calliphoridae). J Med Entomol 43: 1023-1033.

7. Wall R, Pitts KM, Smith KE (2001) Pre-adult mortality in the blowfly Lucilia sericata. Med Vet Entomol 15: 328-34.

8. Ireland S, Turner B (2006) The effects of larval crowding and food type on the size and development of the blowfly, Calliphora vomitoria. Forensic Sci Int 159 175-181.

9. Clark K, Evans L, Wall R (2006) Growth rates of the blowfly, Lucilia sericata, on different body tissues. Forensic Sci Int 156: 145-149.

10. Day DM, Wallman JF (2006) Influence of Substrate Tissue Type on Larva Growth in Calliphora augur and Lucilia cuprina (Diptera: Calliphoridae). J Forensic Sci 51: 657-663.

11. Nabity P, Higley L, Heng-Moss T (2006) Effects of temperature on development of Phormia regina (Diptera: Calliphoridae) and use of developmental data in determining time intervals in forensic entomology. J Med Entomol 43: 12761286.

12. Davies L, Ratcliffe GG (1994) Development rates of some pre-adult stages in blowflies with reference to low temperatures. Med Vet Entomol 8: 245-254.

13. Richards CS, Patterson I, Villet MH (2007) Estimating the age of immature Chrysomya albiceps (Diptera: Calliphoridae), correcting for temperature and geographical latitude. Int J Legal Med 22: 271-279.

14. Richards CS, Villet MH (2008) Factors affecting accuracy and precision of thermal summation models of insect development used to estimate postmortem intervals. Int J Legal Med 122: 401-408.

15. Byrd JH, Allen JC (2001) The development of the black blow fly, Phormia regina (Meigen). Forensic Sci Int 120: 79-88.

16. Clarkson CA, Hobischak NR, Anderson GS (2004) A comparison of the development rate of Protophormia terraenovae (Robineau-Desvoidy) raised under constant and fluctuating temperature regimes. Can Soc Forensic Sci J 37: 95-101.

17. Wells JD, LaMotte LR (1995) Estimating maggot age from weight using inverse prediction. J Forensic Sci 40: 585-590.

18. Régnière J (1984) A method of describing and using variability in development rates for the simulation of insect phenology. Can Entomol 116: 1367-1376.

19. Severini M, Baumgartner J, Limonta L (2003) Parameter estimation for distributed delay based population models from laboratory data: egg hatching of Oulema duftschmidi Redthenbacher (Coleoptera, Chrysomelidae) as an example. Ecol Model 167: 233-246.

20. Ikemoto T, Takai K (2000) A new linearized formula for the law of total effective temperature and the evaluation of line-fitting methods with both variables subject to error. Environ Entomol 29: 671-682.

21. Weibull WA (1951) A Statistical distribution function of wide applicability. J App Mech-T ASME 18: 293-297

22. Dourel L, Gaudry E, Pasquerault T, Vincent B. Adult emergences: starting points to estimate the PMI. in 7th Meeting of the EAFE. 2009. Uppsala (Sweden): European Association for Forensic Entomology.

23. Amendt J, Campobasso C, Gaudry E, Reiter C, LeBlanc H, Hall MJR (2006) Best practice in forensic entomology : standards and guidelines. Int $\mathrm{J}$ Lega Med 121: 1-15. 